\title{
ECOLOGICAL ROLE OF ULMUS PUMILA L. IN LIMITATION OF HEAVY METALS INPUT INTO THE ENVIRONMENT OF SOME ANTHROPOGENIC AREAS OF TRANS-BAIKAL TERRITORY
}

(C) 2018

Kopylova Lubov Viktorovna, candidate of biological sciences, associate professor of Ecology, Ecological and Chemistry Education Department Transbaikal State University (Chita, Russian Federation)

Abstract. The paper deals with the most negative pollution of the environment - heavy metal pollution. We describe the main sources of heavy metal input to soils, their form and character of distribution on the surface of land. The paper presents the research data on study of plants' capacity to accumulate different microelements including heavy metals. We study the Trans-Baikal Territory as the oldest mining territory which has been influenced by different anthropogenic factors. The urgency of this study is determined by the fact that it is important to reveal species capable of accumulating heavy metals in their organs and tissues for the purpose of improving and supporting the ecological balance of anthropogenic territories. We describe Siberian elm (Ulmus pumila L.), a tree species often used in urban lands greening. The research findings on determination of content and characteristic features of some heavy metals accumulation in Ulmus pumila L. organs (leaves, roots, bark) in anthropogenic conditions are discussed. We analyze the data on accumulation of heavy metals ( $\mathrm{Zn}, \mathrm{Fe}, \mathrm{Mn}, \mathrm{Ni}, \mathrm{Cu}, \mathrm{Cr}, \mathrm{Sr}, \mathrm{Rb}, \mathrm{Ti}$ ) in soil of test sites and the studied organs of Ulmus pumila L. It has been determined that Ulmus pumila L. accumulates all heavy metals studied in different quantities, accumulating their high concentrations mainly in the root and bark. This species accumulates $\mathrm{Fe}, \mathrm{Sr}, \mathrm{Mn}, \mathrm{Ti}, \mathrm{Zn}$ most of all, it accumulates less quantities of $\mathrm{Rb}, \mathrm{Cu}, \mathrm{Cr}$ и $\mathrm{Ni}$. Excessive accumulation of heavy metals by the studied species is associated with its location. Thus, we have determined the possible use of Ulmus pumila L. as a natural biofilter limiting the input of heavy metals into the anthropogenic territories environment.

Keywords: environmental pollution; chemical elements; heavy metals; accumulation; soil cover; clarke; maximum allowable concentration; anthropogenic territories; urban lands; anthropogenic impact; tree species; Siberian elm; Ulmus pumila L.; Trans-Baikal Territory.

\section{РАЗНООБРАЗИЕ РАСТЕНИЙ И ГРИБОВ КРАСНОЯРСКОГО ЛЕСНИЧЕСТВА В ОКРЕСТНОСТЯХ П. ЖАРЕНЫЙ БУГОР (КРАСНОЯРСКИЙ РАЙОН САМАРСКОЙ ОБЛАСТИ)} (C) 2018

\author{
Кузовенко Оксана Анатольевна, кандидат биологических наук, \\ доцент кафедры экологии, ботаники и охраны природы \\ Корчиков Евгений Сергеевич, кандидат биологических наук, \\ доцент кафедры экологии, ботаники и охраны природы \\ Сочнева Елена Васильевна, студент биологического факультета \\ Самарский национальный исследовательский университет имени академика С.П. Королёва \\ (2. Самара, Российская Федерация)
}

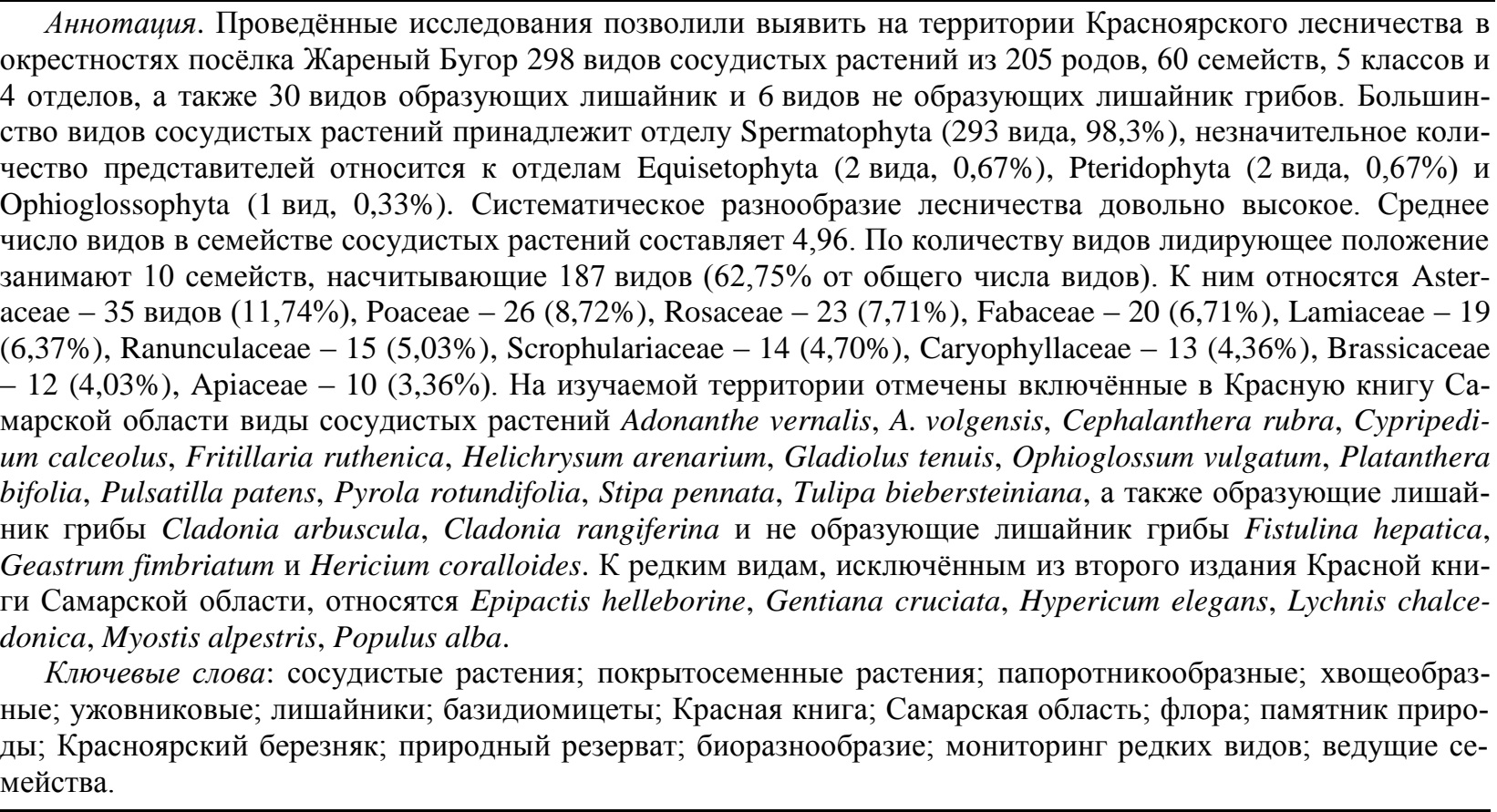


Кузовенко О.А., Корчиков Е.С., Сочнева Е.В.

\section{Введение}

Современный человек уничтожает леса с катастрофической скоростью. Близок тот день, когда на планете не останется коренных сообществ, формировавшихся сотни лет. Однако в Самарской области всё ещё сохраняются небольшие площади лесных массивов, которые можно отнести к сообществам, незначительно затронутым антропогенной деятельностью. Красноярское лесничество занимает площадь более 34 тыс. га. Несмотря на многостороннюю эксплуатацию ресурсов леса, здесь удаётся обнаружить отдельные участки нетронутых сообществ. Ключевую роль в формировании растительного покрова наиболее интересных территорий играет озеро Белое, занимающее центральное положение в квартале (кв.) 99. Близкое залегание грунтовых вод способствует повышенному уровню влажности, способствуя заболачиванию местности, где выделяются нескольких типов сообществ: березняк тростниковоосоковый, разреженный березняк, ивняк и осокорник. На участках, где грунтовые воды залегают на большей глубине, представлены сосняки искусственного происхождения, дубравы с примесью сосны и клёна остролистного, а также разнотравнотипчаковые степи [1, с. 357].

Целью нашей работы было выявление наиболее ценных участков леса с точки зрения его биоразнообразия, в связи с чем была поставлена задача составить конспект сосудистых растений и грибов.

\section{Материал и методы исследования}

Для исследования был выбран небольшой участок леса, земли которого расположены в границах Красноярского лесничества в окрестностях п. Жареный Бугор [2, с. 173]. В период с 2016 по 2018 гг. обследовались 90, 98, 99, 105 кварталы лесничества. Изучение флоры осуществлялось маршрутным методом в различные вегетационные периоды. Посещались все типы сообществ, проводился сбор растений в соответствии с общепринятыми правилами гербаризации [3]. Общий объём гербарных образцов составил свыше 1200 листов. Характерные ландшафты и редкие виды растений фотографировались. На основе собранного материала был составлен конспект флоры, что для данной местности осуществляется впервые [4].

Также для выявления видового состава образующих и не образующих лишайник грибов были обследованы стволы основных лесообразующих пород в данном местообитании: берёзы повислой, осины, сосны обыкновенной, дуба черешчатого, вяза шершавого, черёмухи обыкновенной, а также гниющей древесины по используемой нами ранее общепринятой методике [5]. Для полного выявления видового состава грибов нужно неоднократное посещение данного места в разное время года, а лучше всего многолетние мониторинговые наблюдения, так как формирование плодовых тел большинства базидиомицетов значительно зависит от выпадения осадков. Собранные образцы грибов в лабораторных условиях были определены по следующим определителям [6-13].
Номенклатура таксонов грибов приведена нами по Catalogue of Life [14], а сосудистых растений - по монографии «Флора средней полосы европейской части России» [15].

\section{Результаты исследований и их обсуждение}

Проведённые нами многолетние исследования позволили выявить на территории Красноярского лесничества в окрестностях п. Жареный Бугор 298 видов сосудистых растений из 205 родов, 60 семейств, 5 классов и 4 отделов. Большинство видов принадлежит отделу Spermatophyta (293 вида, 98,3\%), незначительное количество представителей относится к отделам Equisetophyta (2 вида, 0,67\%), Pteridophyta (2 вида, 0,67\%) и Ophioglossophyta (1 вид, 0,33\%). Присутствие во флоре лесничества споровых растений подчёркивает низкий уровень антропогенной нагрузки. Несмотря на небольшое видовое разнообразие этих отделов, они играют важную роль в лесных сообществах.

Систематическое разнообразие лесничества довольно высокое. Среднее число видов в семействе составляет 4,96. По количеству видов лидирующее положение занимают 10 семейств, насчитывающие 187 видов (62,75\% от общего числа видов). К ним относятся Asteraceae - 35 видов (11,74\%), Poaceae $26(8,72 \%)$, Rosaceae - $23(7,71 \%)$, Fabaceae - 20 $(6,71 \%)$, Lamiaceae - 19 (6,37\%), Ranunculaceae - 15 $(5,03 \%)$, Scrophulariaceae - $14(4,70 \%)$, Caryophyllaceae $-13(4,36 \%)$, Brassicaceae - 12 (4,03\%), Apiaceae 10 (3,36\%). Спектр ведущих семейств Самарской области представлен Asteraceae, Poaceae, Fabaceae, Rosaceae, Brassicaceae, Cyperaceae, Lamiaceae, Caryophyllaceae, Scrophulariaceae, Ranunculaceae, Chenopodiaceae, Apiaceae [16, с. 278]. По большинству позиций наблюдается совпадение флор лесничества и региона в целом, однако в головном спектре изучаемой территории отсутствуют Суреraceae и Chenopodiaceaе. Низкое видовое разнообразие Chenopodiaceae демонстрирует ненарушенность лесных экосистем, так как большинство его представителей являются синантропными. Малой изученностью и трудностями сбора материала (произрастание на затопленных участках) объясняется отсутствие Суреraceae среди ведущих семейств.

Нами отмечен ряд редких видов сосудистых растений. Международный статус охраны имеют Cерhalanthera rubra (L.) L.C. Rich. и Cypripedium calceolus L. [17]. Cypripedium calceolus встречается небольшими группами в кв. 105, приурочен к разреженным березнякам с примесью дуба и осины. В таких же сообществах можно наблюдать единичные особи $C e$ phalanthera rubra. Общая численность довольно высокая (наблюдения 2016 г.), однако в 2018 г. было отмечено значительное снижение цветущих особей, что, вероятно, связано с низкими ночными температурами в начале июня. Данные виды, а также Fritillaria ruthenica Wikstrom и Stipa pennata L. s. str. включены в Красную книгу Российской Федерации [18]. Также все вышеназванные виды включены в Красную книгу Самарской области [19]. 
Кроме того, на изучаемой территории отмечены охраняемые на региональном уровне [19] сосудистые растения Adonanthe vernalis (L.) Spach, A. volgensis (Steven ex DC.) Chrtec et Slavikova, Helichrysum arenarium (L.) Moench, Gladiolus tenuis M. Bieb., Ophioglossum vulgatum L., Platanthera bifolia (L.) L.C. Rich., Pulsatilla patens (L.) Mill., Pyrola rotundifolia L., Tulipa biebersteiniana Schultes et Schultes fil.

В разреженных березняках, осокорниках по берегам озера Белого и вдоль дорог в широколиственном лесу нами отмечено обильное цветение и плодоношение Platanthera bifolia. Многолетние наблюдения показывают, что численность популяций достаточно высокая и стабильная.

Наиболее ценной находкой для изучаемого участка леса является обнаруженная здесь в 2016 г. крупнейшая в Самарской области популяция Ophioglossum vulgatum. В благоприятные годы численность достигает 135 особей на $1 \mathrm{M}^{2}$ (наблюдения 20172018 гг.). По предварительным оценкам общая численность популяции в Красноярском лесничестве может составлять до 7-8 тыс. особей. Ophioglossum vulgatum - реликт растительности третичного периода, современные данные о произрастании которого в Самарской области известны только по флористическим исследованиям Красносамарского лесничества [20, с. 719].

Следует отметить перечень раритетных видов сосудистых растений, произрастающих на территории лесничества, но по разным причинам исключённых из Красной книги Самарской области. К ним относятся Epipactis helleborine (L.) Crantz, Gentiana cruciata L., Hypericum elegans Steph., Lychnis chalcedonica L., Myostis alpestris F.W. Schmidt (M. popovii Dobrocz.), Populus alba L. [19, c. 368-372].

Предварительные результаты изучения видового разнообразия образующих и не образующих лишайник грибов Красноярского лесничества в окрестностях п. Жареный Бугор показали уже на данном этапе изучения его ценность, так как здесь выявлено обитание 2 видов лишайников (Cladonia arbuscula, C. rangiferina) и 3-х видов грибов (Fistulina hepatica, Geastrum fimbriatum, Hericium coralloides), занесённых в новое издание Красной книги Самарской области (табл. 1). Все найденные виды, за исключением Fistulina hepatica, которая регистрируется спорадически по всему лесничеству, но исключительно на дубах, встречаются единичными особями в единичных местообитаниях. Всего же здесь выявлено обитание тридцати видов образующих лишайник грибов, относящихся к восемнадцати родам, девяти семействам, пяти порядкам, двум классам Arthoniomycetes и Lecanoromycetes из отдела Ascomycota, а также шести видов не образующих лишайник грибов.

Сравнивая видовое разнообразие грибов изученных субстратов, отметим, что существенное разнообразие их характерно для коры дуба черешчатого, берёзы повислой и черёмухи обыкновенной, на которых обитает подавляющее большинство выявленных видов.

Таблица 1 - Видовое разнообразие образующих лишайник и не образующих лишайник грибов Красноярского лесничества в окрестностях п. Жареный Бугор на разных типах субстрата

\begin{tabular}{|c|c|c|c|c|c|c|c|c|c|}
\hline \multirow[b]{2}{*}{$\begin{array}{l}\text { № } \\
\Pi / \Pi\end{array}$} & \multirow[b]{2}{*}{ Вид } & \multicolumn{8}{|c|}{ Субстрат } \\
\hline & & $\begin{array}{c}\text { Kopa } \\
\text { Betula } \\
\text { pendula }\end{array}$ & $\begin{array}{l}\text { Kopa } \\
\text { Quercus } \\
\text { robur }\end{array}$ & $\begin{array}{c}\text { Kopa } \\
\text { Ulmus } \\
\text { glabra }\end{array}$ & $\begin{array}{c}\text { Kopa } \\
\text { Pinus } \\
\text { sylvestris }\end{array}$ & $\begin{array}{l}\text { Kopa } \\
\text { Padus } \\
\text { avium }\end{array}$ & $\begin{array}{c}\text { Поч- } \\
\text { ва }\end{array}$ & $\begin{array}{l}\text { Гниющая } \\
\text { древесина }\end{array}$ & $\begin{array}{c}\text { Ли- } \\
\text { шайни- } \\
\text { ки }\end{array}$ \\
\hline \multicolumn{10}{|c|}{ Образующие лишайник грибы } \\
\hline 1 & $\begin{array}{l}\text { Amandinea punctata (Hoffm.) } \\
\text { Coppins et Scheid. }\end{array}$ & & + & & & & & & \\
\hline 2 & Buellia schaereri De Not. & & & & + & & & & \\
\hline 3 & $\begin{array}{l}\text { Candelariella efflorescens } \\
\text { R.C. Harris et W.R. Buck }\end{array}$ & + & + & & & + & & & \\
\hline 4 & $\begin{array}{l}\text { *Cladonia arbuscula (Wallr.) } \\
\text { Flot. subsp. arbuscula }\end{array}$ & & & & & & + & + & \\
\hline 5 & $\begin{array}{l}\text { Cladonia botrytis (K.G. Hagen) } \\
\text { Willd. }\end{array}$ & & & & & & & + & \\
\hline 6 & Cladonia fimbriata (L.) Fr. & + & + & & & & & + & \\
\hline 7 & $\begin{array}{l}\text { Cladonia macilenta Hoffm. } \\
\text { subsp. macilenta }\end{array}$ & & + & & & & & + & \\
\hline 8 & $\begin{array}{l}\text { *Cladonia rangiferina }(\mathrm{L} .) \\
\text { Weber ex F.H. Wigg. subsp. } \\
\text { rangiferina }\end{array}$ & & & & & & + & & \\
\hline 9 & Evernia mesomorpha Nyl. & + & + & & & & & & \\
\hline 10 & Evernia prunastri (L.) Ach. & + & + & & & & & & \\
\hline 11 & Hypogymnia physodes (L.) Nyl. & + & + & & & + & & & \\
\hline 12 & $\begin{array}{l}\text { Lecanora chlarotera Nyl. } \\
\text { subsp. chlarotera }\end{array}$ & & + & & & & & & \\
\hline 13 & $\begin{array}{l}\text { Lecanora saligna (Schrad.) Za- } \\
\text { hlbr. var. saligna }\end{array}$ & + & + & & & + & & & \\
\hline 14 & Lepraria jackii Tønsberg & & + & & & & & & \\
\hline 15 & $\begin{array}{l}\text { Melanelixia subargentifera } \\
\text { (Nyl.) O. Blanco, A. Crespo, } \\
\text { Divakar, Essl., D. Hawksw. et } \\
\text { Lumbsch }\end{array}$ & & + & & & + & & & \\
\hline
\end{tabular}


Кузовенко О.А., Корчиков Е.С., Сочнева Е.В.

\begin{tabular}{|c|c|c|c|c|c|c|c|c|c|}
\hline \multirow[b]{2}{*}{$\begin{array}{c}\text { № } \\
\Pi / \Pi\end{array}$} & \multirow[b]{2}{*}{ Вид } & \multicolumn{8}{|c|}{ Субстрат } \\
\hline & & $\begin{array}{c}\text { Kopa } \\
\text { Betula } \\
\text { pendula }\end{array}$ & $\begin{array}{l}\text { Kopa } \\
\text { Quercus } \\
\text { robur }\end{array}$ & $\begin{array}{l}\text { Kopa } \\
\text { Ulmus } \\
\text { glabra }\end{array}$ & \begin{tabular}{|c|} 
Kopa \\
Pinus \\
sylvestris
\end{tabular} & $\begin{array}{l}\text { Kopa } \\
\text { Padus } \\
\text { avium }\end{array}$ & $\begin{array}{l}\text { Поч- } \\
\text { ва }\end{array}$ & $\begin{array}{l}\text { Гниющая } \\
\text { древесина }\end{array}$ & $\begin{array}{c}\text { Ли- } \\
\text { шайни- } \\
\text { ки }\end{array}$ \\
\hline 16 & $\begin{array}{l}\text { Melanelixia subaurifera (Nyl.) } \\
\text { O. Blanco, A. Crespo, Divakar, } \\
\text { Essl., D. Hawksw. Et Lumbsch }\end{array}$ & & & & & + & & & \\
\hline 17 & $\begin{array}{l}\text { Melanohalea exasperatula } \\
\text { (Nyl.) O. Blanco, A. Crespo, } \\
\text { Divakar, Essl., D. Hawksw. et } \\
\text { Lumbsch }\end{array}$ & & & & & + & & & \\
\hline 18 & Opegrapha varia Pers. & & & + & & & & & \\
\hline 19 & $\begin{array}{l}\text { Parmelia sulcata Taylor var. } \\
\text { sulcata }\end{array}$ & + & + & & & + & & & \\
\hline 20 & $\begin{array}{l}\text { Phaeophyscia nigricans } \\
\text { (Flörke) Moberg }\end{array}$ & + & + & & & & & & \\
\hline 21 & $\begin{array}{l}\text { Phaeophyscia orbicularis } \\
\text { (Neck.) Moberg }\end{array}$ & + & + & & & & & & \\
\hline 22 & Phlyctis argena (Spreng.) Flot. & & & & & + & & & \\
\hline 23 & $\begin{array}{l}\text { Physcia adscendens (Fr.) } \\
\text { H. Olivier }\end{array}$ & + & + & & & + & & & \\
\hline 24 & $\begin{array}{l}\text { Physcia dubia (Hoffm.) Lettau } \\
\text { var. dubia }\end{array}$ & & & & & + & & & \\
\hline 25 & Physcia stellaris (L.) Nyl. & + & + & & & & & & \\
\hline 26 & $\begin{array}{l}\text { Physcia tenella (Scop.) DC. } \\
\text { subsp. tenella }\end{array}$ & & + & & & + & & & \\
\hline 27 & $\begin{array}{l}\text { Physconia distorta (With.) } \\
\text { J.R. Laundon var. distorta }\end{array}$ & & + & & & & & & \\
\hline 28 & $\begin{array}{l}\text { Physconia enteroxantha (Nyl.) } \\
\text { Poelt }\end{array}$ & & + & & & + & & & \\
\hline 29 & Rinodina pyrina (Ach.) Arnold & & + & & & & & & \\
\hline 30 & Xanthoria parietina (L.) Beltr. & & + & + & & & & & \\
\hline \multicolumn{10}{|c|}{ Не образующие лишайник грибы } \\
\hline 1 & $\begin{array}{l}\text { Athelia arachnoidea (Berk.) } \\
\text { Jülich }\end{array}$ & & & & & & & & + \\
\hline 2 & $\begin{array}{l}\text { *Fistulina hepatica (Schaeff.) } \\
\text { With. }\end{array}$ & & + & & & & & & \\
\hline 3 & Fomes fomentarius (L.) Fr. & + & & & & & & & \\
\hline 4 & *Geastrum fimbriatum Fr. & & & & & & + & & \\
\hline 5 & $\begin{array}{l}\text { *Hericium coralloides (Scop.) } \\
\text { Pers. }\end{array}$ & & & & & & & + & \\
\hline 6 & Phellinus igniarius (L.) Quél. & & + & & & & & & \\
\hline & Всего: & 12 & 23 & 2 & 1 & 12 & 3 & 5 & 1 \\
\hline
\end{tabular}

Примечание: * - вид занесён в Красную книгу Самарской области [19].

\section{Выводы}

Таким образом, в Красноярском лесничестве в окрестностях п. Жареный Бугор произрастает не менее 298 видов сосудистых растений, относящихся к 205 родам, 60 семействам, 5 классам и 4 отделам, а также 30 видов образующих лишайник и 6 видов не образующих лишайник грибов, в том числе 18 охраняемых видов: занесённые в Красную книгу РФ Cephalanthera rubra, Cypripedium calceolus, Fritillaria ruthenica, Stipa pennata; занесённые в Красную книгу Самарской области Adonanthe vernalis, A. volgensis, Helichrysum arenarium, Gladiolus tenuis, Ophioglossum vulgatum, Platanthera bifolia, Pulsatilla patens, Pyrola rotundifolia, Tulipa biebersteiniana, Cladonia arbuscula, C. rangiferina, Fistulina hepatica, Geastrum fimbriatum, Hericium coralloides. С учётом вышесказанного, а также благодаря контрастному рельефу с высокими грядами, занятыми дубравами в одних местах, с неСамарский научный вестник. 2018. Т. 7, № 4 (25) большими по площади сосновыми посадками и близкому залеганию грунтовых вод в других местах, занятых ивняками, осокорниками и мокрыми березняками, заслуживает отнесения к особо ценной категории леса, а кварталы № 90, 98, 99 и 105 целесообразно обеспечить региональной охраной, организовав здесь памятник природы регионального значения «Красноярский березняк».

\section{Список литературы:}

1. Проект организации и развития лесного хозяйства Красноярского лесхоза лесного управления лесами // Федеральная служба лесного хозяйства России западное государственное лесоустроительное предприятие «Брянсклеспроект» / сост. И.С. Глушенков, В.М. Бокунов, А.И. Пехтерев, В.А. Яшина. Самара, 1995. $357 \mathrm{c.}$

2. Кузовенко О.А., Сочнева Е.В. Обзор флоры в окрестностях Красноярского лесничества (Краснояр- 
ский район Самарской области) // Природное наследие России: сб. науч. ст. Пенза, 2017. С. 173-175.

3. Щербаков А.В., Майоров С.Р. Инвентаризация флоры и основы гербарного дела: методические рекомендации. М., 2006. 50 с.

4. Саксонов С.В., Сенатор С.А. Путеводитель по Самарской флоре (1851-2011). Флора Волжского бассейна. Тольятти: Кассандра, 2012. Т. 1. 511 с.

5. Корчиков Е.С. Лишайники Самарской Луки и Красносамарского лесного массива. Самара: Самарский университет, 2011. 320 с.

6. Бондарцева М.А. Определитель грибов России. Порядок афиллофоровые. Вып. 2. СПб.: Наука, 1998. $391 \mathrm{c.}$

7. Николаева Т.Л. Ежовиковые грибы // Флора споровых растений СССР. М.; Л.: АН СССР, 1961. T. VI. $433 \mathrm{c}$.

8. Сосин П.Е. Определитель гастеромицетов СССР. Л.: Наука, 1973. 164 с.

9. Определитель лишайников России: Agriaceae, Anamylopsoraceae, Arthrorhaphidaceae, Brigantiaeaceae, Chrysotrichaceae, Clavariaceae, Ectolechiaceae, Gomphillaceae, Gypsoplacaceae, Lecanoraceae, Mycoblastaceae, Phlyctidaceae, Physciaceae, Pilocarpaceae, Ramalinaceae, Stereocaulaceae, Vezdeaceae, Tricholomataceae / под ред. Н.С. Голубковой. СПб.: Наука, 2008. Вып. 10. 512 с.

10. Определитель лишайников России: Фусцидеевые, Телохистовые / под ред. М.П. Андреева, Е.Г. Ромса. СПб.: Наука, 2004. Вып. 9. 339 с.

11. Определитель лишайников СССР: Веррукариевые-Пилокарповые / под ред. М.Ф. Макаревич. Л.: Наука, 1977. Вып. 4. 344 с.

\section{VARIETY OF PLANTS AND FUNGI \\ OF THE KRASNOYARSK FORESTRY NEAR THE ZHARENYI BUGOR VILLAGE}

(C) 2018
12. Определитель лишайников СССР: Кладониевые - Акараспоровые / под ред. Н.С. Голубковой, Х.Х. Трасса. Л.: Наука, 1978. Вып. 5. 304 с.

13. Определитель лишайников СССР: Пертузариевые, Леканоровые, Пармелиевые / под ред. М.Ф. Макаревич. Л.: Наука, 1971. Вып. 1. 412 с.

14. Catalogue of Life, 31st July 2018 [El. resource] // Species 2000 \& ITIS / ed. by Y. Roskov, T. Orrell, D. Nicolson [et al.]. - http://catalogueoflife.org/col.

15. Маевский П.Ф. Флора средней полосы европейской части России. М.: Товарищество научных изданий КМК, 2014. 600 с.

16. Сосудистые растения Самарской области / под ред. А.А. Устиновой и Н.С. Ильиной. Самара: Содружество, 2007. 400 с.

17. Конвенция о международной торговле видами дикой фауны и флоры, находящимися под угрозой исчезновения (подписана 3 марта 1973 г. в г. Вашингтон) // СИТЕС в России. Охрана живой природы. Нижний Новгород, 1995. Вып. 5. С. 6-52.

18. Красная книга Российской Федерации (растения и грибы) / сост. Р.В. Камелин и др. М.: Товарищество научных изданий КМК, 2008. 855 с.

19. Красная книга Самарской области. Редкие виды растений и грибов / под ред. С.А. Сенатора и С.В. Саксонова. Самара: Издательство Самарской государственной областной академии (Наяновой), 2017. T. $1.284 \mathrm{c}$.

20. Корчиков Е.С., Матвеев Н.М., Плаксина Т.И., Прохорова Н.В., Макарова Ю.В. Orchidaceae и Ophioglossaceae в лесах степного Заволжья // Известия Самарского научного центра Российской академии наук. 2010. Т. 12, № 1 (3). С. 717-720.

\author{
Kuzovenko Oksana Anatolyevna, candidate of biological sciences, \\ associate professor of Ecology, Botany and Nature Protection Department \\ Korchikov Evgeniy Sergeevich, candidate of biological sciences, \\ associate professor of Ecology, Botany and Nature Protection Department \\ Sochneva Elena Vasilyevna, student of Faculty of Biology \\ Samara National Research University (Samara, Russian Federation)
}

Abstract. There are 298 species of vascular plants from 205 genera, 60 families, 5 classes and 4 divisions, as well as 30 species of lichen-forming and 6 species of non-lichen-forming fungi in the Krasnoyarsk forestry near the Zharenyi Bugor village. Most species of vascular plants belong to the divisio of Spermatophyta (293 species, 98,3\%), a small number of species belong to the divisio of Equisetophyta ( 2 species, $0,67 \%)$, Pteridophyta ( 2 species, $0,67 \%$ ) and Ophioglossophyta (1 species, $0,33 \%)$. The taxonomical diversity of Krasnoyarsk forestry is quite high. The average number of species in the family of vascular plants is 4,96. There are 10 families, which occupy the leading position, including 187 species $(62,75 \%$ of the total number of species): Asteraceae -35 species $(11,74 \%)$, Poaceae -26 (8,72\%), Rosaceae - 23 (7,71\%), Fabaceae - 20 (6,71\%), Lamiaceae - 19 (6,37\%), Ranunculaceae $15(5,03 \%)$, Scrophulariaceae - 14 (4,70\%), Caryophyllaceae - 13 (4,36\%), Brassicaceae - 12 (4,03\%), Apiaceae - $10(3,36 \%)$. On the study area, the species of vascular plants Adonanthe vernalis, A. volgensis, Cephalanthera rubra, Cypripedium calceolus, Fritillaria ruthenica, Helichrysum arenarium, Gladiolus tenuis, Ophioglossum vulgatum, Platanthera bifolia, Pulsatilla patens, Pyrola rotundifolia, Stipa pennata, Tulipa biebersteiniana, as well as lichen-forming fungi Cladonia arbuscula, Cladonia rangiferina and non-lichen-forming fungi Fistulina hepatica, Geastrum fimbriatum, Hericium coralloides are in the Red Book of the Samara Region. The rare species excluded from the second edition of the Red Book of the Samara Region are Epipactis helleborine, Gentiana cruciata, Hypericum elegans, Lychnis chalcedonica, Myostis alpestris, Populus alba.

Keywords: vascular plants; angiosperm plants; ferns; horsetails; ophioglossophyta; lichens; basidiomycetes; Red book; Samara Region; flora; nature reservation; Krasnoyarsk birch forest; nature reserve; biodiversity; monitoring of rare species; leading families. 